\title{
Mineral intakes in Irish pre-school children aged 1-4 years
}

\author{
F. Browne ${ }^{1}$, J. Walton ${ }^{1}$, B. McNulty ${ }^{2}$, A. Nugent ${ }^{2}$, M. Gibney ${ }^{2}$ and A. Flynn ${ }^{1}$ \\ ${ }^{1}$ Irish Universities Nutrition Alliance (IUNA) at; School of Food and Nutritional Sciences, University College Cork, \\ Republic of Ireland and ${ }^{2}$ UCD Institute of Food and Health, University College Dublin, Belfield, Dublin 4, \\ Republic of Ireland
}

It is well established that nutrition in infancy and childhood is fundamental for future health status. The objective of the study was to estimate mineral intakes and the contribution of different food groups to mineral intakes in Irish pre-school children and was based on the Nation Pre-school Nutrition Survey (2010-2011), which was carried out to establish a database of habitual food and drink consumption in a representative sample of Irish pre-school children aged 1-4 years. A 4 day weighed food record was used to collect food intake data from 500 pre-school children. Analysis of dietary intake data was carried out using WISP ${ }^{\odot}$ (Tinuviel Software, Anglesey, UK), which is based on McCance and Widdowson's The Composition of Foods, Sixth Edition ${ }^{(1)}$. and the Irish Food Composition Database ${ }^{(2)}$. For selected minerals, the mean daily intake and the percentage of individuals with intakes less than the UK estimated average requirement $(\mathrm{EAR})^{(3)}$ are reported. Under-reporters were excluded from the analysis. Minimum energy intake cut-off points ${ }^{(4)}$ (Torun et al. 1996), calculated as multiples of $\mathrm{BMR}^{(5)}$ (Schofield et al. 1985) were used to identify under-reporters.

\begin{tabular}{|c|c|c|c|c|c|c|c|c|c|c|c|c|}
\hline & \multicolumn{3}{|c|}{1 year olds $(n=107)$} & \multicolumn{3}{|c|}{2 year olds $(n=91)$} & \multicolumn{3}{|c|}{3 year olds $(n=81)$} & \multicolumn{3}{|c|}{4 year olds $(n=95)$} \\
\hline & Mean & SD & $\%<$ EAR & Mean & SD & $\%<$ EAR & Mean & $\mathrm{SD}$ & $\%<$ EAR & Mean & SD & $\%<$ EAR \\
\hline \multicolumn{13}{|l|}{ Minerals } \\
\hline Calcium(mg) & 878 & 294 & 0.0 & 840 & 281 & 0.0 & 795 & 281 & 0.0 & 785 & 222 & 0.0 \\
\hline $\operatorname{Iron}(\mathrm{mg})$ & 7.4 & 3.0 & 23.4 & 7.9 & 2.9 & 9.9 & 7.7 & 4.1 & 11.1 & 8.1 & 2.7 & 0.0 \\
\hline $\operatorname{Magnesium}(\mathrm{mg})$ & 150 & 36 & 0.0 & 167 & 40 & 0.0 & 166 & 35 & 0.0 & 174 & 44 & 0.0 \\
\hline Zinc(mg) & 5.6 & 1.7 & 8.4 & 5.8 & 1.9 & 13.2 & 5.6 & 1.8 & 12.3 & 5.6 & 1.4 & 38.9 \\
\hline Copper(mg) & 0.6 & 0.3 & $\mathrm{n} / \mathrm{a}$ & 0.7 & 0.3 & $\mathrm{n} / \mathrm{a}$ & 0.8 & 0.4 & $\mathrm{n} / \mathrm{a}$ & 0.8 & 0.3 & $\mathrm{n} / \mathrm{a}$ \\
\hline Phosphorus(mg) & 848 & 225 & $\mathrm{n} / \mathrm{a}$ & 909 & 249 & $\mathrm{n} / \mathrm{a}$ & 885 & 219 & $\mathrm{n} / \mathrm{a}$ & 908 & 203 & $\mathrm{n} / \mathrm{a}$ \\
\hline $\operatorname{Potassium}(\mathrm{mg})$ & 1790 & 410 & $\mathrm{n} / \mathrm{a}$ & 1858 & 440 & $\mathrm{n} / \mathrm{a}$ & 1866 & 384 & $\mathrm{n} / \mathrm{a}$ & 1895 & 371 & $\mathrm{n} / \mathrm{a}$ \\
\hline
\end{tabular}

The key sources of selected minerals are shown in the table below.

\begin{tabular}{ll}
\hline Minerals & Main food groups and their percentage contribution \\
Calcium (mg) & Milk \& yoghurt, 53\%; bread \& rolls, 10\%; breakfast cereals, $8 \%$ \\
Iron (mg) & Breakfast cereals, 31\%; bread \& rolls, 13\%; meat \& meat products, $11 \%$ \\
Magnesium (mg) & Milk \& yoghurt, 25\%; fruit \& fruit juices, $15 \%$; breakfast cereals, $12 \%$ \\
Zinc (mg) & Milk \& yoghurt, 31\%; meat \& meat products, 23\%; bread \& rolls, $9 \%$ \\
Copper (mg) & Fruit \& fruit juices, 25\%; meat \& meat products, 13\%; bread \& rolls, $12 \%$ \\
Phosphorus (mg) & Milk \& yoghurt, 38\%; meat \& meat products, 15\%; breakfast cereals, $8 \%$ \\
Potassium (mg) & Milk \& yoghurt, 29\%; fruit \& fruit juices, $21 \%$; meat \& meat products, $13 \%$ \\
\hline
\end{tabular}

Intakes of selected minerals in 1-4 year old Irish children are generally adequate with the exception of iron and zinc. Iron intakes were below the EAR for almost a quarter of 1 year olds. Zinc intakes were also seen to be below the EAR particularly in 4 year olds. "Milk \& Yoghurt", "Breakfast Cereals", "Meat \& Meat Products", "Fruit \& Fruit Juices" and "Bread \& Rolls" are the main contributors to mineral intakes in Irish pre-school children.

The project was funded by the Irish Government under the Food for Health Research Initiative 2007-2012.

1. Food Standards Agency. McCance \& Widdowson's The Composition of Foods Sixth Edition including supplemental volumes. Cambridge: Royal Society of Chemistry; 2002.

2. Black LJ, Ireland J, Moller A, Roe M, Walton J, Flynn A et al. (2011) Development of an on-line Irish food composition database for nutrients. J. Food Compos. Anal. 24(7): 1017-1023.

3. Department of Health UK. Dietary Reference Values for Food Energy and Nutrients for the United Kingdom. No. 41. London: H.M. Stationary Office; 1991.

4. Torun B, Davies PSW, Livingstone MBE, Paolisso M, Sackett R \& Spurr GB (1996) Energy requirements and dietary recommendations for children and adolescents 1 to 18 years old. Eur. J. Clin. Nutr 50, S37-S81.

5. Schofield WN (1985) Predicting basal metabolic rate, new standards and review of previous work. Hum. Nutr. Clin. Nutr. 39C, Suppl 1; 5-41. 